\title{
A STUDY OF IMMUNOTHERAPEUTIC EFFICACY OF TRICHINELLA SPIRALIS EXCRETORY-SECRETORY PROTEINS IN MURINE TRICHINELLOSIS
}

\author{
By
}
TAHANY ABD ALLAH MOHAMED AL-ATTAR, WAFAA MOHAMED EL-KERSH, GEHAN SALAH SADEK, NANCY MAHMOUD HARBA, SALWA FOUAD OSHEIBA AND REHAM MUSTAFA BRAKAT*

Department of Parasitology, Faculty of Medicine, Menoufia University, Shebin ElKom, Egypt ( ${ }^{*}$ Correspondence: reham_brakat@yahoo.com, Mobile: 002010047744222)

\begin{abstract}
Trichinellosis is a serious zoonotic parasitic and globally endemic disease. Benzimidazole derivatives are apparently unable to kill encapsulated larvae and its effectiveness depends on solubility, dosage of therapy, host biotransformation, selectivity patterns as well as onset of treatment after infection. Excretory-secretory (ES) proteins released by Trichinella induce a strong immune response when tested as a vaccine. The current study investigated both therapeutic and protective effects of adult worm excretory secretory protein (AW/ES), or larval excretory secretory protein (LES) on T. spiralis infected mice, conducted by parasitological, histopathological, immunohistochemical, serological and molecular investigations. Larval excretory secretory protein achieved more significant therapeutic and protective effects than adult worm excretory secretory protein in experimentally infected mice, causing reduction in larval counts and decrease in pathological changes of both muscular and intestinal tissues. It increased serum IgG OD values, decreased Foxp3 expressions and increased the mean cycle thres- hold values of muscular tissues but it had lesser effects on adult worm counts than albendazole.

Key words: Mice, Trichinella spiralis, Immunotherapeutic efficacy, Excretory-secretory proteins

\section{Introduction}

Trichinellosis is a parasitic zoonosis caused by Trichinella spiralis, a serious endemic disease worldwide (CDC, 2017). Human infection commonly occurred by eating raw or undercooked pork containing Trichinella larvae. Pork and its products were associated with human trichinellosis outbreaks (Wang et al, 2017). The global prevalence of trichinellosis is difficult to be evaluated, but about 11 million people may be infected (Lee et al, 2016). Trichinellosis was reported in at least 55 countries (Pozio, 2007), where the annual number of clinical cases was estimated to be 10000 with $0.2 \%$ death rate (Got-tstein et al, 2009). Life cycle alternates bet-ween enteric and muscle phases (Zhan et al, 2013).

Trichnella antigens were divided into the surface, excretory secretory (ES) and residual somatic antigens. Excretory secretory antigens are glycoproteins in nature excreted/ secreted from larvae or adults of Trichinella. The major sources of ES products include not only the molecules released from specialized excretory or secretory organs but

also the material shed from the cuticular and tegumental surfaces (Zhang et al, 2018).

Immunization with ES protein elicits a robust immune response and high protection against trichinellosis. Some studies showed that pig's inoculation with $T$. spiralis larval ES antigens could significantly reduce the adult worm burden. T. spiralis ES proteins offer promising targets for vaccines development (Goyal et al, 1997). The protective effect was via active lymphocyte proliferative responses \& cytokine production. The Th2 type interleukin (IL)-10, IL-4 \& IL-5 were the predominant cytokines (Robinson et al, 1995a; Quan et al, 2004; Yang et al, 2018). Administration of efficacious antihelminthic drugs at the stage of intestinal invasion was very important to have a better outcome. Antihelminthic drugs such as mebendazole and albendazole are commonly used in treatment but none was fully effective against the encysted $T$. spiralis or the newborn larvae. So, there was a great need to develop new safe antihelminthic to treat trichinellosis (Saad et al, 2016).

Generally, immunotherapy is the therapeu-
\end{abstract}


tic approach that targets or manipulates the immune system. It controls the host's adaptive and innate immune response to provide a long-lived elimination of diseased cells. It is categorized broadly into passive (adoptive $\&$ antibody-based) and active (vaccine therapy \& allergen-specific) approaches (Papaioannou et al, 2016). Active immunotherapy induces the patient's immune response resulting in development of specific immune effectors (antibodies and T cells) which control the disease (Naran et al, 2018).

The present study aimed to evaluate the therapeutic and protective effects of Trichnella excretory/secretory (ES) proteins on enteral and muscle phase in Trichinella spiralis infected mice.

\section{Materials and Methods}

Preparation and isolation of ES antigens: Trichinella spiralis strain was obtained from laboratory bred infected albino mice in Parasitology Department, Faculty of Medicine, Tanta University. Infected muscles were cut excised $(2 \mathrm{~cm})$, and digested with pepsin solution (Pepsin $1 \mathrm{~g} / \mathrm{HCl} 1 \mathrm{ml} /$ distilled water to $100 \mathrm{ml}$ ) for 12 hours. Freshly T. spiralis larvae were isolated by the stereomicroscope. Twenty mice were infected for ES antigens preparation, each with about $300 \mathrm{~T}$. spiralis infective larvae (Korenaga et al, 2001).

Ten mice were sacrificed on $8^{\text {th }}$ day post infection (dpi), adult worms (AW) were collected from the upper two-thirds (duodenum and jejunum) of small intestine. They were washed five times in PBS with 100U penici$1 \mathrm{in} / \mathrm{ml}$ and $100 \mu \mathrm{g}$ streptomycin $/ \mathrm{ml}$ and then cultured at $37{ }^{\circ} \mathrm{C}$ in RPMI 1640 (medium containing 10\% fetal bovine serum) and 5\% $\mathrm{CO}_{2}$ for $18 \mathrm{~h}$. After incubation, the supernatant contained AW/ES antigens were obtained by centrifugation at $4^{\circ} \mathrm{C}, 11,000 \mathrm{~g}$ for 20 min (Wang et al, 2017).

At $35^{\text {th }}$ day post infection (dpi), another ten mice were sacrificed; larvae of $T$. spiralis were isolated from mice muscle tissue by artificial digestion, and then washed. Clean larvae were incubated in a $\mathrm{CO}_{2}$ incubator for $24 \mathrm{~h}$ at $37^{\circ} \mathrm{C}$ in Petri-dish contained RPMI-
1640 culture medium. Supernatants were collected by centrifugation, and dialyzed to get larval ES antigens (Wang et al, 2014).

Ethics Statement: All animals were treated according to Theodor Bilharz Research Institute ethics. They were kept under standard conditions in TBRI animal house maintained on a standard commercial pelleted diet in an air-conditioned room at $20-22^{\circ} \mathrm{C}$. All experimental procedures were performed in accordance with the international ethical guidelines approval by TBRI Ethical Committee.

Animals and Study Design: A total of 140 Swiss male albino mice aged two months and weighed $25 \pm 0.2 \mathrm{gm}$ were used. They were divided into 7 groups of 20 mice each. GI: Non-infected, non-vaccinated and nontreated mice, GII: Infected non-vacciated and non-treated mice, each one received 300 T. spiralis infective larvae. GIII: Vaccinated with AW/ES antigen, 100 $\mu \mathrm{g}$ in PBS injected subcutaneously 7 days before oral infection with 300 T. spiralis muscle larvae (Dea-Ayuela and Bolas-Fernández, 2000). GIV: Vaccinated with larval ES antigen $100 \mu \mathrm{g}$ in PBS injected subcutanously 7 days before oral infection with $300 \mathrm{~T}$. spiralis muscle larvae. $\mathrm{GV}$ : Infected and treated with $25 \mu \mathrm{g}$ of AW/ ES antigen injected intraperitoneally for 7 days starting from the $1^{\text {st }}$ infection day. GVI: Infected and treated with $25 \mu \mathrm{g}$ of larval ES antigen injected intraperitoneally for 7 days starting from the $1^{\text {st }}$ infection day (Yang et $a l$, 2014). Both GV \& GVI were immunotherapy groups.

GVII: Infected and treated with albendazole (suspension $20 \mathrm{mg} / \mathrm{ml}$, Egyptian International Pharmaceutical Industries Co.) $50 \mathrm{mg} /$ $\mathrm{kg} /$ day orally starting from the $1^{\text {st }}$ infection day for three successive days (Bakir et al, 2017). Each group was further subdivided according to the time of scarification into 2 equal subgroups (10 mice each) at the $8^{\text {th }} \mathrm{dpi}$ named (SGs Ia, IIa, IIIa, IVa, Va, VIa, VIIa) to evaluate the enteral phase and at the $35^{\text {th }}$ dpi named (SGs Ib, IIb, IIIb, IVb, Vb, VIb, VIIb) to evaluate the muscular phase.

Parasitological assessment was carried out 
by isolation and counting of adult worms in the small intestine of all groups at $8^{\text {th }}$ dpi by a microscope $\times 10$ (Quan et al, 2008). Also, by collection and counting of larvae from all groups at $35^{\text {th }}$ dpi, larvae were microscopically counted using a McMaster counting chamber (Saad et al, 2016).

Histopathological study: Mice of first subgroups were sacrificed at $8^{\text {th }}$ dpi and specimens from small intestine were collected. Mice of second subgroups were sacrificed at $35^{\text {th }}$ dpi and muscles specimens were collected, fixed in $10 \%$ formalin, embedded in paraffin, sectioned and stained with haematoxylin and eosin (Goyal et al, 2013).

Immunohistochemical study: Paraffin sections $4 \mu$ thickness from muscle tissue blocks of all groups were stained by immunohistochemical method for Forkhead box (Foxp$3+) \mathrm{T}$ regulatory (T-regs) after Eissa et al, (2016). Immunohistochemical identification of foxP3+Treg cells was done using rat antifoxp3 antibody, clone 150D/E4 (eBioscience, Vienna, Austria). Kit was ultravision detection system anti-polyvalent horseradish peroxidase/diaminobenzidine tetra-hydrochloride (HRP/DAB). Muscle tissue sections were deparaffinized, hydrated, subjected to microwave antigen retrieval in citrate buffer for $15 \mathrm{~min}$., blocked for endogenous peroxidase, and then they were exposed to primary antibody (antifoxp3) for $3 \mathrm{hrs}$ at a dilution of 1:50. Biotinylated goat anti-polyvalent was applied for an hr, and then streptavidin biotin was applied for $20 \mathrm{~min}$. The chromogen used was DAB. A minimum of 3 high power fields (HPFs x400) were counted for each section and positive cells were expressed as mean number of positive cells /HPF. Positive Foxp3 staining was identified when cell membrane alone or together with cytoplasm showed brown staining, whereas, negative was considered without membrane staining.

The staining intensity (Fraser et al, 2003) was scored: mild $=1+$, moderate $=2+$, strong $=$ $3+$. The stained slides were evaluated quantitatively using the $\mathrm{H}$-score. Briefly, staining intensity was given a number $(1+, 2+\& 3+)$ for mild, moderate and strong staining respectively. Stained cells percent in each tissue was multiplied by staining intensity. A score of 0-300 was given for stained biomarker after the following equation $\mathrm{H}$ score $=[1 \times(\%$ cells $1+)+2 \times(\%$ cells $2+)+3 \times$ $(\%$ cells $3+)]$.

ELISA for serum total specific IgG level (Arana et al, 2012): Before scarification of mice at $35^{\text {th }}$ dpi, blood samples were taken for estimation of serum level of specific indirect ELISA IgG antibodies in sera of mice. Maxsorp 96-well microtitre plates (Nunc, Denmark) were coated with $125 \mu \mathrm{g} / \mathrm{ml}$ of ES antigen in carbonate-bicarbonate buffer, $\mathrm{pH}$ 9.4 overnight at $4^{\circ} \mathrm{C}$. Plates were blocked with $250 \mu \mathrm{l} /$ well of $2 \%$ bovine serum albumin diluted in PBS, $\mathrm{pH} 7.2$, with $0.05 \%$ Tween-20 (PBS/BSA/T-20) for $2 \mathrm{hr}$ at room temperature. Sera were diluted 1:100 in PBS/ T-20, loaded into plates $(100 \mu \mathrm{l} /$ well), and incubated at room temperature for an hr. After washing, $100 \mu \mathrm{l} /$ well of alkaline phosphatase (AP)-conjugated anti-mouse IgG (Southern Biotech, USA, $1 \mathrm{mg} / \mathrm{ml}$ each) diluted in PBS/T-20 (1:5000 for IgG) were added for $90 \mathrm{~min}$. Reaction developed by adding $100 \mu \mathrm{l} /$ well of p-nitrophenyl phosphate substrate (Sigma-Aldrich, UK) and incubation until appearance of yellow color. Absorbance was read at $405 \mathrm{~nm}$ using an ELISA reader (BioRad, UK) (El-Aswad et al, 2019).

Molecular study: By real-time polymerase chain reaction (PCR) for detection of $T$. spiralis larva DNA in muscular tissue (Cuttell et al, 2012).

Genomic DNA was extracted from muscular frozen tissue using JET ${ }^{\mathrm{TM}}$ Genomic DNA Purification Mini Kit (THERMO SCIENTIFIC, EU/Lithuania). Samples were digested with Proteinase $\mathrm{K}$ in lysis solution. The lysate was mixed with ethanol and loaded on the purification column where DNA binds to the silica membrane. Impurities were effectively removed by washing the column with the prepared wash buffers. Genomic DNA was then eluted under low ionic strength conditions with the elution buffer. PCR for 
T. spiralis gene was evaluated to a total volume of $25 \mathrm{ul}$ contained $10 \mathrm{ul}$ of genomic DNA, 2.5ul of 10x Taq polymerase buffer, 1.5ul 2mM MgCl2, 0.25ul Taq DNA polymerase (5units/ $\mu \mathrm{l}$ ) (Genecraft, Germany), $0.5 \mathrm{ul}$ of dNTPS (10mM) (Stratagene, USA), $1 \mathrm{ul}$ of each primer $(20 \mu \mathrm{M})$ (Midland, Texas) \& 8.25ul of $\mathrm{H}_{2} \mathrm{O}$ using the primers, Forward primer 5- CATGGTTAGGTGAGATATTGCCTGC-3, Reverse primer 5-GGTCCTCCTTCCAGAAGATCTACTTTG-3. Real-time PCR assay was performed on a Rotor-Gene 6000 (Corbett Research) real-time PCR cycler in the Central Lab, Faculty of Medicine, Menoufia University. Total reaction volume was $10 \mu$ l contained $5 \mu 12 \times$ Sensi-Mix Plus SYBR $^{\circledR}$ Green (Quantace Ltd.). PCR primers were optimized for use at 300nM \& 100 ng of DNA was added to each reaction. Samples were always twice PCR replication. Cycling profile included an initial denaturation at $95^{\circ} \mathrm{C} / 10 \mathrm{~min}$, then 40 cycles of $95^{\circ} \mathrm{C} /$ $10 \mathrm{~s}, 62^{\circ} \mathrm{C} / 15 \mathrm{~s} \& 72 \circ \mathrm{C} / 20 \mathrm{~s}$. Fluorescence was measured in green channel and data collected at the extension step. Cycle threshold $(\mathrm{Ct})$ values were individually calculated by internal software using a manual threshold setting of $0.2 \&$ 'dynamic tube' and 'ignore first 10 cycles' functions were activated. A melt-curve analysis was done after each run in order to match amplicons with positive control melt curve peaks and confirm specificity. Cycle threshold in muscular tissue was inversely proportional to the amount of larval DNA detected by real-time PCR.

Statistical analysis: Data were coded, tabulated and analyzed using SPSS (20), IBM Corp. Released 2011 (IBM SPSS Statistics for Windows, Version 20.0). Armonk, NY: IBM Corp. Data were of quantitative type, expressed in mean and standard deviation (SD). Mann Whitney's test was used for comparison of quantitative variables between two groups. Post Hoc Value was used to assess the difference in two means of two individual groups. Significance level was $95 \%$, so, p-value $>0.05$ was not significant difference; $p$-value $<0.05$ was considered a statistically significant difference.

\section{Results}

A significant reduction of $T$. spiralis adult worm count was recorded in all vaccinated and treated subgroups as compared to infected subgroup. There was a significant difference between both vaccinated SGs (IIIa $\&$ Iva respectively) $(\mathrm{P} 6<0.05)$ and a significant difference between both groups treated with ES (Va \& VIa respectively) (P13 < $0.05)$. There was a significant difference between albendazole treated SG VIIa \& both treated SGs with AW/ES (Va) \& larval ES antigens (VIa) (P14\& P15<0.001) \& vaccinated SGIIIa with AW/ES (P9<0.001), but when comparing albendazole treated SG VIIa with vaccinated SG IVa with larval ES antigen, without significant difference (P12 $>0.05$ ). A significant difference was between vaccinated SGIVa with larval ES \& treated SGVa with AW/ES (P10<0.001), but without significant difference with treated with larval ES SGVIa (P11>0.05). But, no significant difference was between vaccinated SGIIIa by AW/ES with treated SGs with AW/ES or larval ES (Va \& VIa respectively) (P7>0.05\& P8 $>0.05)$.

Larval count, a significant reduction in $T$. spiralis larval percent was in all vaccinated (IIIb \& IVb) and treated (Vb \& VIb) as compared with infected (SGIIb). Also, a significant difference was between all vaccinated and treated mice, except difference between AW/ES treated SGVb \& albendazole treated SGVIIb was non-significant (P14 >0.05).

Histopathological results: There was a significant decrease in the inflammation intensity in intestinal tissues in all vaccinated and treated groups as compared to infected control (SGIIa). Also, significant differences were detected between albendazole treated (SGVIIa) and both SGIIIa vaccinated with AW/ES antigen $(\mathrm{P} 9<0.05) \& \mathrm{SGVa}$ treated with AW/ES antigen $(\mathrm{P} 14<0.05)$.

Histopathological results: muscle tissues showed a decrease in intensity of larval deposition in all vaccinated and treated subgroups with significant differences between 
them and infected non-vaccinated non-treated (SGIIb). There were significant differences between vaccinated with larval ES antigen (SGIVb) \& treated with AW/ES antigen $(\mathrm{SGVb})(\mathrm{P} 10<0.05)$ and albendazole treated (SGVIIb) $(\mathrm{P} 12<0.05)$. There were significant differences between larval ES antigen treated (SGVIb) and those treated with AW/ES antigen $(\mathrm{SGVb})(\mathrm{P} 13<0.05)$ or albendazole treated SGVIIb (P15<0.05).

Immunohistochemical results: Highest \% of FoxP3 expression and intensity (H-Score) was in infected non-treated (SGIIb) (136 9.66). Differences among subgroups were significant except mice vaccinated with larval ES antigen (SGIVb) and larval ES treated (SGVIb) was non-significant (P11>0.05).

Serological results: Serum IgG OD values in vaccinated subgroups showed the highest one was in subgroup vaccinated with larval ES antigen SGIVb (0.69 \pm 0.094$)$, followed by vaccinated with $\mathrm{AW} / \mathrm{ES}$ antigen SGIIIb $(0.5760 \pm 0.11)$. In treated subgroups, highest serum IgG OD value was in mice treated with larval ES antigen SGVIb (0.39 \pm 0.056$)$ followed by mice treated with AW/ES antigen $\mathrm{SGVb}(0.29 \pm 0.06)$ then albendazole treated mice SGVIIb $(0.15 \pm 0.045)$. There were significant differences between all subgroups except between the infected SGIIb and albendazole treated SGVIIb.

Real time PCR: Value of cycle threshold was inversely proportional to DNA concentration. There was significant reduction of $T$. spiralis larval DNA concentration in vaccinated SGIIIb \& SGIVb. Cycle threshold highest value was in mice vaccinated with larval ES protein SGIVb (35.6 \pm 1.32$)$, but mice vaccinated with adult ES protein SG IIIb the cycle threshold value was $(29.95 \pm$ $0.00)$. As to treatment, highest value was in mice treated with larval ES protein (SGVIb) $(30.8 \pm 0.042)$. In mice treated with albendazole (SGVIIb), cycle threshold value was (23.57 \pm 0.013$)$ but mice treated with adult ES antigen (SGVb) was $15.2 \pm 0.08$, with significant reductions of $T$. spiralis larval DNA concentrations in all vaccinated and treated subgroups as compared to SGIIb. Details were given in tables $(1,2 \& 3)$ and figures

Table 1: Comparison of the mean count of $T$. spiralis adult worm at $8^{\text {th }}$ dpi among all groups:

\begin{tabular}{|c|c|c|c|c|c|c|}
\hline \multirow{2}{*}{ Groups ( $\mathrm{n}=10$ each) } & \multicolumn{3}{|c|}{ Adult count } & \multirow{2}{*}{$\begin{array}{c}\text { Reduction } \\
\%\end{array}$} & \multirow{2}{*}{ Mann Whitney test } & \multirow{2}{*}{ P.value } \\
\hline & $\mathrm{M} \pm \mathrm{SD}$ & Median & Range & & & \\
\hline $\begin{array}{l}\text { SGIIa } \\
\text { (Infected group) }\end{array}$ & $50.2 \pm 5.09$ & 50 & $40-55$ & $0 \%$ & $\begin{array}{l}\text { IIa } v s \text { IIIa }=3.814 \\
\text { IIa } v s \text { IVa }=3.822\end{array}$ & $\begin{array}{l}\mathrm{P} 1<0.001 * * \\
\mathrm{P} 2<0.001 * *\end{array}$ \\
\hline $\begin{array}{l}\text { SGIIIa } \\
\text { (Vaccinated with AW/ES \& infected) }\end{array}$ & $8.2 \pm 3.4$ & 9.5 & $0-12$ & $83.7 \%$ & $\begin{array}{l}\text { IIa } v s \mathrm{Va}=3.817 \\
\text { IIa } v s \mathrm{VIa}=3.810\end{array}$ & $\begin{array}{l}\mathrm{P} 3<0.001 * * \\
\mathrm{P} 4<0.001 * *\end{array}$ \\
\hline $\begin{array}{l}\text { SGIVa } \\
\text { (Vaccinated with L/ES \& infected) }\end{array}$ & $4.2 \pm 3.1$ & 5 & $0-8$ & $91.6 \%$ & $\begin{array}{l}\text { IIa } v s \text { VIIa }=3.857 \\
\text { IIIa } v s \text { IVa }=2.758\end{array}$ & $\begin{array}{l}\mathrm{P} 5<0.001^{* *} \\
\mathrm{P} 6<0.05^{*}\end{array}$ \\
\hline $\begin{array}{l}\text { SGVa } \\
\text { (Infected \& treated with AW/ES) }\end{array}$ & $10 \pm 2.35$ & 10.5 & $5-12$ & $80.1 \%$ & $\begin{array}{l}\text { IIIa } v s \text { Va }=1.469 \\
\text { IIIa } v s \text { VIa }=1.657\end{array}$ & $\begin{array}{l}\mathrm{P} 7>0.05 \\
\mathrm{P} 8>0.05\end{array}$ \\
\hline $\begin{array}{l}\text { SGVIa } \\
\text { (Infected \& treated with L/ES) }\end{array}$ & $6.6 \pm 2.45$ & 6 & $2-10$ & $86.9 \%$ & $\begin{array}{l}\text { IIIa } v s \text { VIIa }=3.340 \\
\text { IVa } v s \text { Va }=3.307\end{array}$ & $\begin{array}{l}\mathrm{P} 9<0.001 * * \\
\mathrm{P} 10<0.001 * *\end{array}$ \\
\hline $\begin{array}{l}\text { SGVIIa } \\
\text { (Infected \& treated with Albendazole) }\end{array}$ & $1.7 \pm 2.35$ & 0 & $0-5$ & $96.6 \%$ & $\begin{array}{l}\text { IVa } v s \text { VIa }=1.818 \\
\text { IVa } v s \text { VIIa }=1.867 \\
\text { Va } v s \text { VIa }=2.608 \\
\text { Va } v s \text { VIIa }=3.747 \\
\text { VIa } v s \text { VIIa }=3.368\end{array}$ & $\begin{array}{l}\mathrm{P} 11>0.05 \\
\mathrm{P} 12>0.05 \\
\mathrm{P} 13<0.05 * \\
\mathrm{P} 14<0.001 * * \\
\mathrm{P} 15<0.001 * *\end{array}$ \\
\hline
\end{tabular}

P1: comparison between SGIIa \& IIIa, P2: between IIa \& IVa, P3: between IIa \& Va, P4: between IIa \& VIa, P5: GIa \& VIIa, P6: between IIIa \& IVa, P7: between IIIa \& Va, P8 between IIIa \& VIa, P9: between IIIa \& VIIa, P10: between IVa \&Va, P11: between IVa \& VIa, P12: between IVa \& VIIa, P13: between Va \& VIa, P14: between Va \& VIIa, P15: between VIa \& VIIa. 
Table 2: Comparison of mean count of Trichinella spiralis larvae at $35^{\text {th }}$ dpi among all groups:

\begin{tabular}{|c|c|c|c|c|c|c|}
\hline \multirow[b]{2}{*}{ Groups ( $\mathrm{n}=10$ each) } & \multicolumn{3}{|c|}{ Larval count } & \multirow{2}{*}{$\begin{array}{c}\text { Reduction } \\
\%\end{array}$} & \multirow{2}{*}{ Mann Whitney test } & \multirow[b]{2}{*}{ P. value } \\
\hline & Mean \pm SD & Median & Range & & & \\
\hline $\begin{array}{l}\text { SGIIb } \\
\text { (Infected group) }\end{array}$ & $101650 \pm 9945.6$ & 100200 & $\begin{array}{c}90000- \\
12000 \\
0\end{array}$ & 0 & $\begin{array}{l}\text { IIb vs } b=3.785 \\
\text { IIb vs } I V b=3.79 \\
\text { IIb vs } V b=3.787\end{array}$ & $\begin{array}{l}\mathrm{P} 1<0.001 * * \\
\mathrm{P} 2<0.001 * * \\
\mathrm{P} 3<0.001 * *\end{array}$ \\
\hline $\begin{array}{l}\text { SGIIIb } \\
\text { (Vaccinated with AW/ES \& infected) }\end{array}$ & $32350 \pm 2505.6$ & 31150 & $\begin{array}{c}30000- \\
7000\end{array}$ & $68.2 \%$ & $\begin{array}{l}\text { Ilb vs VIb }=3.79 \\
\text { IIb vs VIIb }=3.784\end{array}$ & $\begin{array}{l}\mathrm{P} 4<0.001^{* *} \\
\mathrm{P} 5<0.001 * * \\
\mathrm{P} 6<0.001 * *\end{array}$ \\
\hline $\begin{array}{l}\text { SGIVb } \\
\text { (Vaccinated with L/ES \& infected) }\end{array}$ & $3972 \pm 1681.6$ & 3650 & $\begin{array}{c}1200- \\
5000\end{array}$ & $96.1 \%$ & $\begin{array}{l}\text { IIIb vs } I V b=3.375 \\
\text { IIIb vs } V b=2.245 \\
\text { IIIb vs } V I b=3.192\end{array}$ & $\begin{array}{l}\mathrm{P} 6<0.001^{* *} \\
\mathrm{P} 7<0.05^{*} \\
\mathrm{P} 8<0.001^{* *}\end{array}$ \\
\hline $\begin{array}{l}\text { SGVb } \\
\text { (Infected \& treated gr with AW/ES) }\end{array}$ & $37130 \pm 1965.28$ & 37100 & $\begin{array}{c}35000- \\
40000\end{array}$ & $63.5 \%$ & $\begin{array}{l}\text { IIIb vs VIIb }=2.113 \\
\text { IVb vs Vb }=3.576 \\
\text { IVb vs VIb }=2.975\end{array}$ & $\begin{array}{l}\mathrm{P} 9<0.05^{*} \\
\mathrm{P} 10<0.001^{* *} \\
\mathrm{P} 11<0.001^{* *}\end{array}$ \\
\hline $\begin{array}{l}\text { SGVIb } \\
\text { (Infected \& treated with L/ES) }\end{array}$ & $12230 \pm 6002.97$ & 12600 & $\begin{array}{l}5000- \\
20000\end{array}$ & $87.96 \%$ & $\begin{array}{l}\text { IVb vs VIb }=2.975 \\
I V b \text { vs VIIb }=3.429 \\
\text { Vb vs VIb }=3.094\end{array}$ & $\begin{array}{l}\mathrm{P} 11<0.001^{* *} \\
\mathrm{P} 12<0.001 * * \\
\mathrm{P} 13<0.001 * *\end{array}$ \\
\hline $\begin{array}{l}\text { SGVIIb } \\
\text { (Infected \& treated with Albendazole) }\end{array}$ & $35760 \pm 1742.41$ & 35100 & $\begin{array}{l}33000- \\
38200\end{array}$ & $64.8 \%$ & $\begin{array}{l}\text { Vb vs VIIb }=1.634 \\
\text { VIb vs VIIb }=3.091\end{array}$ & $\begin{array}{l}\mathrm{P} 14>0.05 \\
\mathrm{P} 15<0.001 * *\end{array}$ \\
\hline
\end{tabular}

P1: comparison between Subgroups IIb \& IIIb, P2: between IIb \& IVb, P3: between IIb \& Vb, P4: between IIb \& VIb, P5: IIb \& VIIb, P6: between IIIb \& IVb, P7: between IIIb \& Vb, P8: between IIIb \& VIb, P9: between IIIb \& VIIb, P10: between IVb \& Vb, P11: IVb \& VIb, P12: between IVb \& VIIb, P13: between Vb \& VIb, P14: between Vb \& VIIb, P15: between VIb \& VIIb.

Table 3: Comparison of mean of IgG OD serum values among all groups at the $35^{\text {th }} \mathrm{dpi}$ :

\begin{tabular}{|c|c|c|c|c|c|}
\hline \multirow{2}{*}{$\begin{array}{l}\text { Groups } \\
(\mathrm{n}=10 \text { each })\end{array}$} & \multicolumn{3}{|c|}{ Serum $\operatorname{IgG}(\mathrm{OD}$ at $450 \mathrm{~nm})$} & \multirow{2}{*}{$\begin{array}{l}\text { MannWhitney } \\
\text { Test }\end{array}$} & \multirow[t]{2}{*}{ P. value } \\
\hline & Mean \pm SD & Median & Range & & \\
\hline $\begin{array}{l}\text { SGIb } \\
\text { (Normal control) }\end{array}$ & 0.065 & 0.065 & 0.065 & $\begin{array}{l}\text { IIb } v s \mathrm{IIIb}=3.787 \\
\mathrm{IIb} v s \mathrm{IVb}=3.804\end{array}$ & $\begin{array}{l}\mathrm{P} 1<0.001 * * \\
\mathrm{P} 2<0.001 * *\end{array}$ \\
\hline $\begin{array}{l}\text { SGIIb } \\
\text { (Infected) }\end{array}$ & $0.1950 \pm 0.074$ & 0.2 & $0.1-0.3$ & $\begin{array}{l}\mathrm{IIb} v s \mathrm{Vb}=2.395 \\
\mathrm{IIb} v s \mathrm{VIb}=3.732\end{array}$ & $\begin{array}{l}\mathrm{P} 3<0.05^{*} \\
\mathrm{P} 4<0.001 * *\end{array}$ \\
\hline $\begin{array}{l}\text { SGIIIb } \\
\text { (Vaccinated with AW/ES \& infected) }\end{array}$ & $0.5760 \pm 0.11$ & 0.6 & $0.4-0.73$ & $\begin{array}{l}\mathrm{IIb} v s \mathrm{VIIb}=1.469 \\
\mathrm{IIIb} v s \mathrm{IVb}=2.369\end{array}$ & $\begin{array}{l}\mathrm{P} 5>0.05 \\
\mathrm{P} 6<0.05 * \\
\mathrm{P} 7<0001 * *\end{array}$ \\
\hline $\begin{array}{l}\text { SGVb } \\
\text { (Vaccinated with L/ES \& infected) }\end{array}$ & $0.69 \pm 0.094$ & 0.7 & $0.5-0.8$ & $\begin{array}{l}\mathrm{IIIb} \text { vs } \mathrm{VIb}=3.326 \\
\mathrm{IIIb} \text { vs } \mathrm{VIIb}=3.803\end{array}$ & $\begin{array}{l}\mathrm{P} 8<0.001 * * \\
\mathrm{P} 9<0.001 * *\end{array}$ \\
\hline $\begin{array}{l}\mathrm{SGVb} \\
\text { (Infected and treated with AW/ES) }\end{array}$ & $0.29 \pm 0.06$ & 0.30 & $0.20-0.40$ & $\begin{array}{l}\mathrm{IVb} v s \mathrm{Vb}=3.822 \\
\mathrm{IVb} v s \mathrm{VIb}=3.783\end{array}$ & $\begin{array}{l}\mathrm{P} 10<0.001 * * \\
\mathrm{P} 11<0.001 * *\end{array}$ \\
\hline $\begin{array}{l}\text { SGVIb } \\
\text { (Infected and treated with L/ES) }\end{array}$ & $0.39 \pm 0.056$ & 0.40 & $0.30-0.50$ & $\begin{array}{l}\mathrm{IVb} v s \mathrm{VIIb}=3.824 \\
\mathrm{Vb} v s \mathrm{VIb}=2.867\end{array}$ & $\begin{array}{l}\mathrm{P} 12<0.001^{* *} \\
\mathrm{P} 13<0.05^{*}\end{array}$ \\
\hline $\begin{array}{l}\text { SGVIIb } \\
\text { (Infected and treated with Albendazole) }\end{array}$ & $0.15 \pm 0.045$ & 0.14 & $0.10-0.20$ & $\begin{array}{l}\mathrm{Vb} \text { vs } \mathrm{VIIb}=3.419 \\
\mathrm{VIb} \text { s } \mathrm{VIIb}=3.802\end{array}$ & $\begin{array}{l}\mathrm{P} 14<0.001^{* *} \\
\mathrm{P} 15<0.001^{* *}\end{array}$ \\
\hline
\end{tabular}

P1: comparison between Subgroups IIb \& IIIb, P2: between IIb \& IVb, P3: between IIb \& Vb, P4: between IIb \& VIb, P5: IIb \& VIIb, P6: between IIIb \& IVb, P7: between IIIb \& Vb, P8: between IIIb \& VIb, P9: between IIIb \& VIIb, P10: between IVb \& Vb, P11: between IVb \& VIb, P12: between \& VIIb, P13: between Vb \& VIb, P14: between Vb \& VIIb, P15: between VIb \& VIIb.

\section{Discussion}

Trichinellosis is a zoonotic disease associated with severe neurological, ocular and cardiovascular complications and may end fatally. Classical medical treatment included mebendazole or albendazole had a limited effect in treating the muscular phase of $T$. spiralis (Othman and Shoheib, 2016).

The present study evaluated the protective and therapeutic effects of Trichnella ES proteins on enteral and migratory phase of trichinellosis. The protective effect was previously evaluated by many authors, but the therapeutic effect was no used as a therapeutic agent. Crude ES antigens were tested as a vaccine either alone or with adjuvant by many authors (Robinson et al, 1995a; DeaAyuela and Bolas-Fernández, 2000; Quan et $a l, 2004)$. These authors reported that immunization might elicit an effective immune response, resulting in complete protection against infective larvae. Besides, crude ES antigens at variable molecular size had been investigated as immunogens against $T$. spiralis infection and showed effective immune actio in reduction of worm burden (Robinson et al, 1995b; Lightowlers and Rickard, 1998; Nagano et al, 2008; Bi et al, 2015).

In the current study, there was significant reduction of the mean count of adult worms in all vaccinated and treated groups in comparison with the infected group. The better 
outcome was in albendazole treated group followed by the group vaccinated with larval ES. Also, significant $T$. spiralis larval reduction percent was observed in all vaccinated and treated groups in comparison with the infected group. The better outcome was in the group vaccinated with larval ES. The results agreed with Cvetkovic et al. (2016) who reported significant effects of several components of excretory-secretory antigens on dendritic cells in vitro and Lee et al. (2016) who tested protective effect of viruslike particles containing the $53 \mathrm{KDa}$ excretory/secretory proteins of $T$. spiralis and the influenza matrix protein 1 as a core protein, and reported that (ES) proteins played a critical role in modulating host immune system, and elicited a strong immune response and high protection against $T$. spiralis infection. Also, the present results agreed with Quan et al. (2004) who found that immunization of rats with ES Ag of T. spiralis Korean isolate without any adjuvant elicits effective protective immunity against challenge infection. The protective effects involved both adults and larvae and $T$. spiralis ES proteins offer promising targets for vaccines development. The therapeutic effects of ES products of $T$. spiralis were tested in the amelioration of autoimmune, allergic and malignant diseases in vitro and in animal models (Liao et al, 2018). Also, ES products used for treatment of colitis (Smith et al, 2007; Yang et al, 2014), experimental autoimmune encephalomyelitis (Vukman et al, 2016), type 1 diabetes (Liu et al, 2009) and rheumatoid arthritis (Pineda et al, 2012). The results also agreed with Roatt et al. (2017) who evaluated the therapeutic vaccine of antigens of Leishmania braziliensis associated with monophosphoryl lipid A adjuvant for treatment of visceral leishmaniasis, and found that immunotherapy was a significant approach to be used as potential treatment strategy.

In histopathological results of intestinal tissue, there were decrease in the intensity of inflammation in intestinal tissues and larval deposition in muscular tissues of all vaccina- ted group and treated groups compared to infected non-vaccinated non-treated mice. This agreed with Eissa et al. (2003) who used autoclaved $T$. spiralis larval vaccine in combined with BCG as an adjuvant and tested histopathological changes. They found sharp reduction in number of muscle encysted larvae, and were hardly seen as hyalinized cyst surrounded by precystic fibrosis $\&$ mild chronic inflammatory infiltrate, with different inflammatory infiltration surrounding muscle. Also, Yang et al. (2014) found that $\mathrm{AW} / \mathrm{ES}$ treatment decreased the damage score for induced mouse colitis. AW/ES treatment reduced epithelial destruction, edema, and infiltration of inflammatory cells on the colon histological sections.

In the current study, the highest intensity of FoxP3 expression was in infected non-treated mice. Kang et al. (2012) and Cho et al. (2012) reported enhanced production of IL10 , transforming growth factor beta (TGF- $\beta$ ) and proliferation of $\mathrm{T}$ reg cells in $T$. spiralis infected mice. The present data agreed with Ahn et al. (2016) who studied the T reg cells distribution in mice intestine and muscle tissues during $T$. spiralis life cycle. They found the number of activated $\mathrm{T}$ reg cells did not change in muscle tissue for 0 -1 week after infection, and then rapidly increased around the parasite to $4^{\text {th }}$ week of infection when nurse cells were fully developed. Also, The present results agreed with Guo et al. (2016) where $\mathrm{BALB} / \mathrm{c}$ mice were immunized with recombinant $T$. spiralis paramyosin \& CD4+ CD25+Foxp3+ T cells were sorted in immunized mice splenocytes and immunization did not increase in CD4+CD25+Foxp3+ T cells. However, Radovic et al. (2015) found that the percentage of CD4+CD25+Foxp3+ $\mathrm{T}$ cells was higher in the larval ES immunized group than in control one. The present results disagreed with $\mathrm{Xu}$ et al. (2018) who studied the protective and therapeutic role of 2 recombinant $T$. spiralis serine protease inhibitors on induced experimental colitis in mice model, and found percentage of CD4+ CD25+Foxp3+T reg cells in CD4+ T lymph- 
ocytes in spleen and mesenteric lymph nodes were higher than in control ones. This difference may be due to different in studied tissues or different protein used.

In the present study, the highest IgG OD value was in mice vaccinated with larval ES antigen $(0.69 \pm 0.094)$, followed by mice vaccinated with AW/ES antigen $(0.5760 \pm 0.11)$. In treated groups, $t$ highest serum IgG OD value was in mice treated with larval ES antigen $(\mathrm{GVI})(0.39 \pm 0.056)$ followed by mice treated with AW/ES antigen (GV) (0.29土$0.06)$ then albendazole treated mice (GVII) $(0.15 \pm 0.045)$, with significant differences between all groups except between the infected (GII) and albendazole treated (GVII) was non-significant (P5>0.05).

The present results agreed with $\mathrm{Bi}$ et al. (2015) who reported that mice immunized with one $20-\mathrm{kDa}$ protein secreted by $T$. spiralis muscle larvae and adults ES induced protection associated with a high IgG antibody level, as well as increased total IgG, IgG1 \& IgG2a subtypes. Humoral response contributed greatly to resistance against trichinellosis by entrapping and expulsing infective larvae, reducing adults' fecundity \& eliminating newborn larvae. Also, intramuscular immunization of mice with virus-like particles (VLPs) contained $53 \mathrm{kDa}$ ES antigen of $T$. spiralis plus cholera toxin (CT) adjuvant induced specific IgG, IgG1 \& IgG2a antibody responses and significantly reduce worm burden (Lee et al, 2016).

The present results agreed with KołodziejSobocińska et al. (2006) and Dvorožňáková et al. (2010) who found that IgG was the most abundant immunoglobulin in mice and humans. During trichinellosis, IgG- antibodies were involved in inflammatory response to infection, showing an increase during the muscular phase (Pinelli et al, 2007).

As to real time PCR results of this study, there was a decrease in the amount of larval DNA in muscular tissues of all vaccinated and treated groups detected by real-Time PCR. The better outcome was reported in mice vaccinated with larval ES protein.
The present results agreed with Quintana et al. (2016) who used specific primers for detection of $T$. spiralis DNA in muscle by realtime PCR. It has been suggested that specific PCR for T. spiralis may be useful for detection of infection at early stages in humans and food animals. The present results agreed with Cuttell et al. (2012) who used the same primers to measure cycle threshold, and selected to target a conserved region of gene allowing putative amplification of a 195bp fragment of Trichinella. Real-time PCR allowed not only qualitative detection and/or quantitative measurement of parasite DNA, but also the potential to simultaneously differentiate isolates to the species or genotype level. DNA extraction method is sensitive and specific to detect Trichinella larvae in muscle tissue. This agreed with Tantrawatpan et al. (2013) who used a developed probes-based real-time FRET PCR combined with a melting curve analysis to detect $T$. spiralis DNA sequence for mitochondrial small-subunit ribosomal RNA (rRNA) directly in muscle tissue from $T$. spiralis experimentally infected mice by specific prim ers, which proved be used for differentiation of T. spiralis, T. pseudospiralis, and T. papuae by the different Tm values.

\section{Conclusion}

Larval excretory secretory protein has both therapeutic and protective effects on experimental trichinellosis through causing reduction in adult, larval counts and decrease in pathological changes of both muscular and intestinal tissues. Besides, it increased serum IgG OD values, decreased Foxp3 expressions and increased the mean cycle threshold values of muscular tissues.

\section{References}

Ahn, JB, Kang, SA, Kim, DH, Yu, HS, 2016: Activation and recruitment of regulatory $\mathrm{T}$ cells via chemokine receptor activation in Trichinella spiralis-infected mice. Korean J. Parasitol. 54, 2: 163-71.

Arana, JLR, Rodríguez, RC, Aguilar, VR, Gutiérrez, AE, García, AM, et al, 2012: Comparative effects of levamisole, Staphylococcus, and Freund's adjuvant on rat immunization with 
excretory and secretory antigens of Trichinella spiralis muscle larvae. Parasitol. Res. 111:1599605.

Bakir, HY, Attia, RA, Mahmoud, AE, Ibraheim, Z, 2017: M-RNA gene expression of INF$\mathrm{y}$ and IL-10 during intestinal phase of Trichinella spiralis after Myrrh and Albendazole treatment. Iran. J. Parasitol. 12, 2:188-95.

Bi, K, Yang, J, Wang, L, Gu, Y, Zhan, B, et al, 2015: Partially protective immunity induced by a $20 \mathrm{kDa}$ protein secreted by Trichinella spiralis stichocytes. PLoS ONE, 10, 8:1-16.

CDC, 2017: Trichinellosis: DPDx-Laboratory; Identification of Parasites of Public health Concern.

Cho, MK, Park, MK, Kang, SA, Choi, SH, Ahn, SC, et al, 2012: Trichinella spiralis infection suppressed gut inflammation with CD4+ CD25+Foxp3+ T cell recruitment. Korean J. Parasitol. 50, 4:385-90.

Cuttell, L, Corleya, SW, Graya, CP, Vanderlindeb, PB, Jacksonc, LA, $t$ al, 2012: Real-time PCR as a surveillance tool for the detection of Trichinella infection in muscle samples from wildlife. Vet. Parasitol. 188, 3/4: 1-9.

Cvetkovic, J, Sofronic-Milosavljevic, L, Ilic, $\mathrm{N}$, Gnjatovic, M, Nagano, I, et al, 2016: Immunomodulatory potential of particular Trichinella spiralis muscle larvae excretory-secretory components. Int J Parasitol., 46: 833-842.

Dea-Ayuela, MA, Bolas-Fernández, F, 2000: Dynamics of the IgG3 responses following immunisation of $\mathrm{BALB} / \mathrm{c}$ mice with somatic and excretory/secretory antigens from various Trichinella species. Folia Parasitol. 47:172-80.

Dvorožňáková, E, Hurníková, Z, KołodziejSobocińska, M, 2010: Kinetics of specific humoral immune response of mice infected with low doses of Trichinella spiralis, T. britovi, and T. pseudospiralis larvae. Helminthol. 47:152-7.

Eissa, MM, El-Azzouni, MZ, Baddour, NM, Boulos, LM, 2003: Vaccination trial against experimental trichrinellosis using autoclaved Trichinella spiralis larvae vaccine (ATSLV). J. Egypt. Soc. Parasitol. 33, 1:219-28.

Eissa, MM, Mostafa, DK, Ghazy, AA, Elazzouni, MZ, Boulos, LM et al, 2016: Anti-arthritic activity of Schistosoma mansoni and Trichinella spiralis derived- antigens in adjuvant arthritis in rats: role of FOXP3 + Treg cells. PloS One 11, 11:1-20.

El-Aswad, BEW, Harba, NM, Moharm, IM, Mahmoud, SF, 2019: Immunization with adult
Schistosoma mansoni tegument, treated with sub curative praziquantel, partially protects mice against the infection. J. Helminthol. 34:1-12.

Fraser, JA, Reeves, JR, Stanton, PD, Black, D M, Going, JJ, et al, 2003: A role for BRCA1 in sporadic breast cancer. B Cancer J., 88, 8:126370.

Gottstein, B, Pozio, E, No“ckler, K, 2009: Epidemiology, diagnosis, treatment, and control of trichinellosis. Clin. Microbiol. Rev. 22, 1:12745.

Goyal, PK, Bolas-Fernandez, F, Waklin, D, 1997: Immunization of mice against Trichinella spiralis and T. britovi using excretory and secretory antigens. J. Helminthol. 71:1090-12.

Goyal, N, Rishi, P, Shukla, G, 2013: Lactobacillus rhamnosus GG antagonizes Giardia intestinalis induced oxidative stress and intestinal disaccharidases: an experimental study. Wld. Microbiol. Biotechnol. J. 29, 61049e1057.

Guo, K, Sun, X, Gu, Y, Wang, Z, Huang, J, et al, 2016: Trichinella spiralis paramyosin activates mouse bone marrow-derived dendritic cells and induces regulatory $\mathrm{T}$ cells. Parasit. Vect. 9, 569:1-11.

Kang, SA, Cho, MK, Park, MK, Kim, DH, Hong, YC, et al, 2012: Alteration of helper Tcell related cytokine production in splenocytes during Trichinella spiralis infection. Vet Parasitol., 186: 319-327.

Kołodziej-Sobocińska, M, Dvoroznakova, E, Dziemian, E, 2006: Trichinella spiralis: macrophage activity and antibody response in chronic murine infection. Exp. Parasitol. 112: 52-62.

Korenaga, M, Akimaru, Y, Shamsuzzaman, SM, Hashiguchi, Y, 2001: Impaired protective immunity and $\mathrm{T}$ helper 2 responses in alymphoplasia (aly) mutant mice infected with Trichinella spiralis. Immunol. 102:218-24.

Lee, SH, Kim, SS, Lee, DH, Kim, AR, Quan, FS, 2016: Evaluation of protective efficacy induced by virus-like particles containing a Trichinella spiralis excretory-secretory (ES) protein in mice. Parasites Vectors 9, 384:1-9.

Liao, C, Cheng, X, Liu, M, Wang, X, Boireau P, 2018: Trichinella spiralis and tumors: cause, coincidence or treatment? Anti-Can. Agents Med. Chemis.18:1091-9.

Lightowlers, MW, Rickard, MD, 1998: Excretory-secretory products of helminth parasites: Effects on host immune responses. Parasitol. 96, S123-66.

Liu, Q, Sundar, K, Mishra, PK, Mousavi, G, 
Liu, Z, et al, 2009: Helminth infection can reduce insulitis and type 1 diabetes through CD25and IL-10- independent mechanisms. Infect Immun., 77, 12:5347-58.

Nagano, I, Wu, Z, Takahashi, Y, 2008: Species-specific antibody responses to the recombinant 53-kilodalton excretory and secretory proteins in mice infected with Trichinella spp. Clin. Vac. Immunol. 15: 468-73.

Naran, K, Nundalall, T, Chetty, S, Barth, S, 2018: Principles of Immunotherapy: Implications for Treatment Strategies in Cancer and Infectious Diseases. Front. Microbiol. 9, 3158:1-23

Othman, AA, Shoheib, ZS, 2016: Detrimental effects of geldanamycin on adults and larvae of Trichinella spiralis. Helminthol. 53, 2:126-32.

Papaioannou, NE, Beniata, OV, Vitsos, P, Tsitsilonis, O, Samara, P, 2016: Harnessing the immune system to improve cancer therapy. Ann. Transl. Med. 36:199-201.

Pineda, MA, McGrath, MA, Smith, PC, Alriyami, L, Rzepecka, J, et al, 2012: The parasitic helminth product ES-62 suppresses pathogenesis in collagen-induced arthritis by targeting the interleukin-17-producing cellular network at multiple sites. Arthritis Rheum. 64, 10:3168-78.

Pinelli, E, Mommers, M, Kortbeek, LM, Castagna, B, Piergili-Fioretti, D, et al, 2007: Specific IgG4 response directed against the $45 \mathrm{kDa}$ glycoprotein in trichinellosis: a re-evaluation of patients 15 years after infection. Eur. J. Clin. Microbiol. Infect. Dis. 26:641-5.

Pozio, E, 2007: World distribution of Trichinella spp. infections in animals and humans. Vet. Parasitol. 149:13-21.

Quan, FS, Bae, JS, Lee, JB, Min, YK, Yang, HM, et al, 2008: Protective immunity against challenge infection with Trichinella spiralis in the rat. Acta Med. 52:101-6.

Quan, FS, Matsumoto, T, Lee, JB, Timothy, O, Kim, TS, et al, 2004: Immunization with Trichinella spiralis korean isolate larval excretory-secretory antigen induces protection and lymphocyte subset changes in rats. Immunol Invest. 33, 1:15-26.

Quintana, S, Recavarren, M, Scialfa, E, Viera, I, Rivero, M, et al, 2016: Development of a real-time PCR assay for the detection of Trichinella spiralis in muscle tissue of swine and derivatives. J. Food Safety 36: 282-7.

Radovic, I, Gruden, A, Ilic, N, Cvetkovic, J, Mojsilovic, S, 2015: Immunomodulatory effects of Trichinella spiralis-derived excretory-secret- ory antigens. Immuno.l Res. 61:312-25.

Roatt, BM, Aguiar, RD, Reis, LES, Cardoso, JMO, Mathias, FAS, et al, 2017: A vaccine therapy for cannine visceral leishmaniasis promoted significant improvment of clinical and immune status with reduction in parasite burden. Front Immunol. 8:1-14.

Robinson, K, Belaby, T, Chan, WC, Wakelin, D, 1995a: High levels of protection induced by a 40-mer synthetic peptide vaccine against the intestinal nematode parasite Trichinella spiralis. Immunol. 86:495-8.

Robinson, K, Bellaby, T, Wakelin, D, 1995b: Immune response profiles in vaccinated $\&$ nonvaccinated high- and low- responder mice during infection with the intestinal nematode Trichinella spiralis. Parasitol. 110:71-8.

Saad, AE, Ashour, DS, Abou-Rayia, DM, Bedeer, AE, 2016: Carbonic anhydrase enzyme as a potential therapeutic target for experimental trichinellosis. Parasitol Res., 115: 2331-2339.

Smith, P, Mangan, NE, Walsh, CM, Fallon, RE, Mckenzie, ANJ, et al, 2007: Infection with a helminth parasite prevents experimental colitis via a macrophagemediated mechanism. J Immunol., 178: 4557-4566. Human dendritic cell activation. Mol. Immunol. 51: 210-8.

Tantrawatpan, C, Intapan, PM, Thanchomnang, T, Sanpool, O, Janwan, P, et al, 2013: Early detection of Trichinella spiralis in muscle of infected mice by real-time fluorescence resonance energy transfer PCR. Vect-Borne Zoonot. Dis. 13, 9:674-81.

Vukman, KV, Lalor, R, Aldridge, A, O'neill S M, 2016: Mast cells: new therapeutic target in helminth immune modulation. Parasite Immunol. 38, 1:45-52.

Wang L, Cui J, Hu DD, Liu RD, Wang ZQ (2014): Identification of early diagnostic antigens from major excretory-secretory proteins of Trichinella spiralis muscle larvae using immunoproteomics. Parasites \& Vectors 7, 40:1-8. Wang ZQ, Liu RD, Sun GG, Song YY, Jiang, P, et al, 2017: Proteomic analysis of Trichinella spiralis adult worm excretory-secretory proteins recognized by sera of patients with early trichinellosis. Front. Microbiol. 8, 986:1-9.

Xu J, Wu, L, Yu, P, Liu, M, Lu, Y, 2018: Effect of 2 recombinant Trichinella spiralis serine protease inhibitors on TNBS-induced experimental colitis of mice. Clin. Exp. Immunol. 194: 400-13.

Yang X, Yang Y, Wang Y, Zhan B, Gu Y et 
al, 2014: Excretory/Secretory products from Trichinella spiralis adult worms ameliorate DSSinduced colitis in mice. PLoS One 9, 5:1-10.

Yang Z, Li W, Yang Z, Pan A, Liao W, Zhou $X$, 2018: A novel antigenic cathepsin B protease induces protective immunity in Trichinellainfected mice. Vaccine 36:248-55.

\section{Zhan J, Yao J, Liu W, Hu X, Wu Z, Zhou X, 1447-58.}

Fig. 1: Histopathology of intestinal tissues. a- Transverse section in intestinal tissue normal mice (GIa), showed normal leaf like villi and crypts (red arrow) (H\&E) (x100), b- TS in intestinal tissue of infected mice (GIIa), showed severe atrophy and degeneration of crypts (black arrow), severe inflammatory infiltrate (green arrow) and goblet cell hyperplasia (red arrow) (H\&E) (x100), c- TS in intestinal tissue of infected mice (GIIa) showed severe atrophy and degeneration of villi and crypts (red arrow) (H\&E) (x200), d- TS in intestinal tissue of AW/ES vaccinated (GIIIa) showed moderate atrophy and degeneration of some villi (black arrow), moderate inflammatory infiltrate of villi (star) (H\&E) (x400), e- TS in intestinal tissue of LES vaccinated (GIVa) showed mild to moderate inflammatory infiltrate (star) and moderate congestion (black arrow) (H\&E) (x400), f- TS in intestinal tissue of AW/ES treated (GVa) showed moderate to severe atrophy and degeneration of some villi (red arrow), inflammatory infiltrate in corium of villi (star), oedema (green arrow) and congestion (black arrow) (H\&E) (x400), g- TS in intestinal tissue of LES treated (GVIa) showing moderate degeneration of crypts (green arrow), inflammatory infiltrate (star), oedema (red arrow) and congestion of blood vessels (black arrow) (H\&E) (x400), and h-TS in intestinal tissue of albendazole treated group (GVIIa) showing mild atrophy and degeneration of some villi (red arrow) and mild inflammatory $(\mathrm{H} \& \mathrm{E})(\mathrm{x} 400)$.

Fig.2: Histopathology of muscle tissues: a- TS in skeletal muscle tissue of normal (GIb), showed normal appearance of muscle fibers, average distribution of peripherally situated and flattened nuclei (black arrows) (H\& E) (x100), b- TS in skeletal muscle tissue of infected g (GIIb), showed heavy larval deposition $(+3)$ surrounded by dense inflammatory reaction $(+3)$ (black arrows) (H\& E) (x100), c- TS in skeletal muscle tissue of infected (GIIb), showed larval deposition (red arrows) surrounded by dense inflammatory reaction (black arrows) ( +3 ) with degeneration of fibers (green arrow) (H\& E) (x200), d- TS in skeletal muscle tissue of AW/ES vaccinated (GIIIb), showed moderate larval deposition (+2) surrounded by moderate inflammatory reaction (black arrows) (H\& E) (x100), e- TS in skeletal muscle tissue of LES vaccinated (GIVb), showed mild larval deposition (+1) surrounded by mild inflammatory reaction (black arrows) (H\& E) (x100), f- TS in skeletal muscle tissue of AW/ES treated $(\mathrm{GVb})$, showed moderate larval deposition $(+2)$ surrounded by intense inflammatory reaction (black arrows) (H\& E) (x100), g- TS in skeletal muscle tissue of LES treated (GVIb), showed mild larval deposition (+1) (black arrows) surrounded by moderate inflammatory reaction (star) (H\& E) (x100), and h-TS in skeletal muscle tissue of albendazole treated GVIIb), showed moderate larval deposition $(+2)$ surrounded by moderate inflammatory reaction (black arrows) (H\& E) (x100).

Fig.3. Comparison regarding FoxP3 expression: a- TS in skeletal muscle tissue stained with immunohistochemical stain of normal (GIb) showed negative FoxP3 stain expression (black arrows) (x100), b- TS in skeletal muscle tissue of infected (GIlb) showed strong FoxP3 (+3) expression (black arrows) (x100), c- TS in skeletal muscle tissue of AW/ES vaccinated (GIIIb) showed mild to moderate FoxP3 expression (black arrows) (x100), d- TS in skeletal muscle tissue of LES vaccinated (GIVb) showed very mild FoxP3 (+1) expression (black arrows) (x100), e- TS in skeletal muscle tissue of AW/ES treated (GVb) showed moderate FoxP3 (+2) expression (black arrow) (x100), f- TS in skeletal muscle tissue of LES treated (GVIb) showed mild FoxP3 $(+1)$ expression (black arrows) (x100), and g-TS in skeletal muscle tissue stained with immunohistochemical stain of albendazole treated (GVIlb) showed moderate FoxP3 (+2) expression (black arrows) (x100).

Fig 4: $\mathrm{H}$ score and percentage of FoxP3 expression in muscular tissue among groups Fig. 5: Mean of e cycle threshold values PCR among groups.

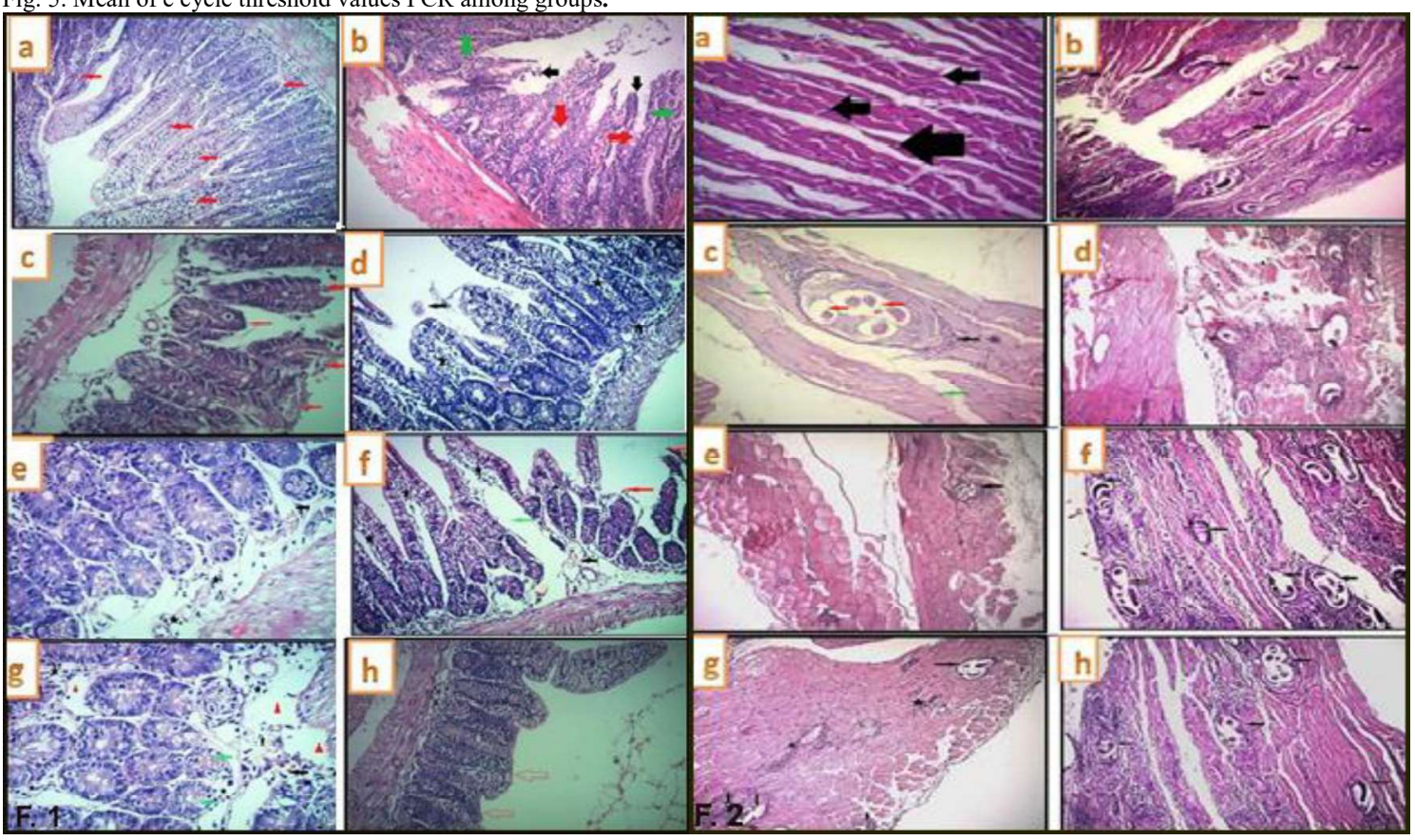



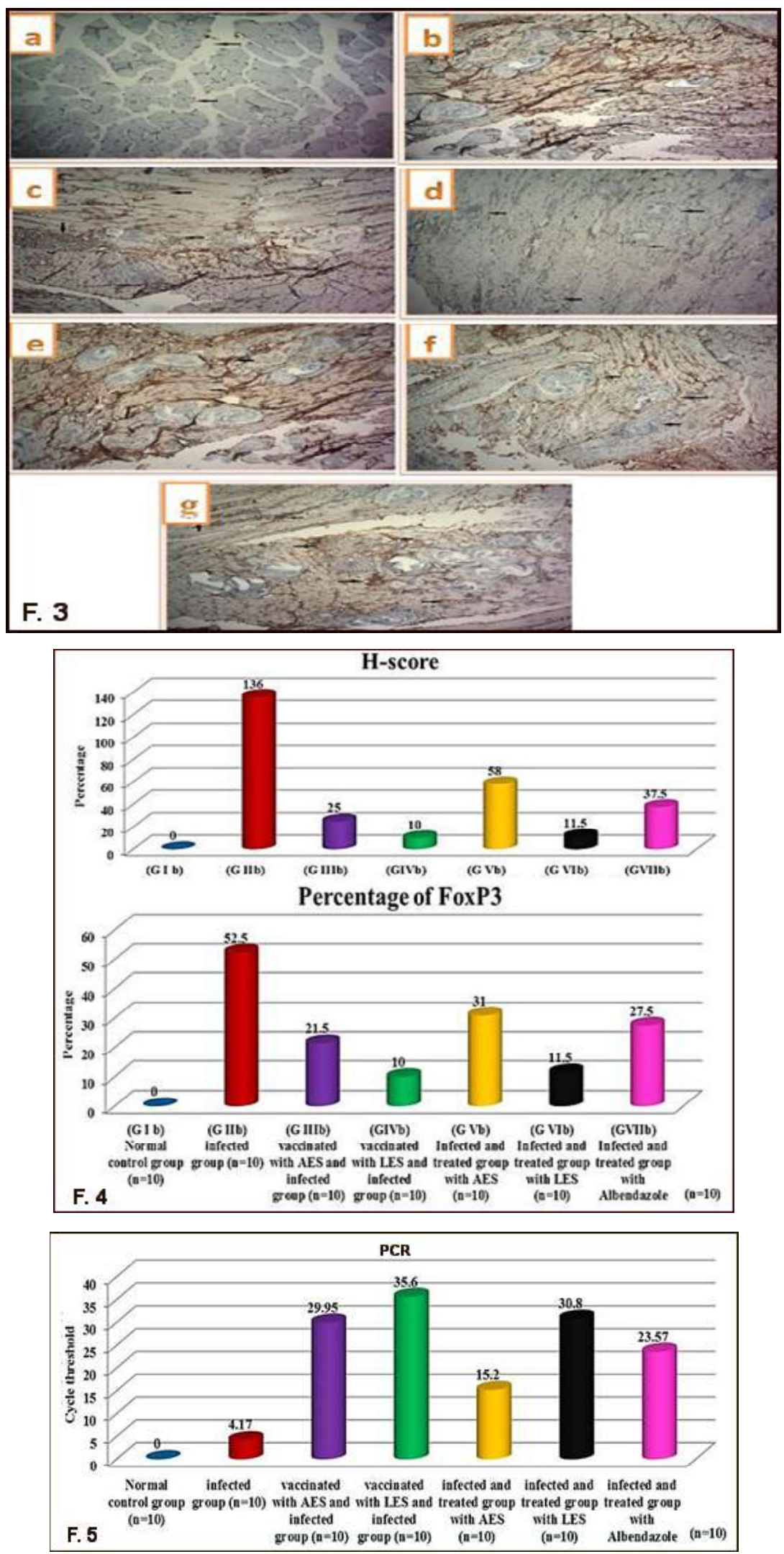